\title{
Navigating the lung for hidden treasure
}

\author{
Cameron D. Wright, MD
}

From the Division of Thoracic Surgery, Massachusetts General Hospital, Boston, Mass.

Disclosures: Author has nothing to disclose with regard to commercial support.

Received for publication May 31, 2018; revisions received May 31, 2018; accepted for publication June 1, 2018; available ahead of print July 11, 2018.

Address for reprints: Cameron D. Wright, MD, Division of Thoracic Surgery, Massachusetts General Hospital, 55

Fruit St, Boston, MA 02114 (E-mail: cdwright@mgh.harvard.edu).

J Thorac Cardiovasc Surg 2018;156:1702-3

0022-5223/\$36.00

Copyright $(C) 2018$ by The American Association for Thoracic Surgery

https://doi.org/10.1016/j.jtcvs.2018.06.017

Small incidentally discovered lung nodules that might be cancer are an increasingly frequent dilemma for thoracic surgeons. Ground-glass lesions add an element of complexity because they are often difficult to palpate at the time of video-assisted thoracic surgery (VATS) exploration. The conversion of lung resection from an open thoracotomy to VATS eliminates the possibility of careful 2-finger palpation of the lung to search for small lung nodules. Numerous adjunctive techniques have been described to facilitate resection of these small lung nodules, including the percutaneous placement with computed tomography (CT) guidance of a hook wire, fiducials, coils, dyes, gelatin, intraoperative ultrasound, and radioactive tracers. ${ }^{1-5}$ Most of these techniques also can be performed with navigation-guided bronchoscopy. Even when these small lesions are localized, it is imperative for the thoracic surgeon to design a resection strategy to facilitate a complete resection of the lesion with adequate margins. As the authors suggest, there remains uncertainty about the definition of an adequate margin, but a commonly accepted one is 1 to $2 \mathrm{~cm}$ or more than twice the diameter of the lesion. This of course does not take into account the histology of the lesion where, for example, a pure lepidic adenocarcinoma likely needs a lessor margin. The thoughtful thoracic surgeon weighs several factors in formulating an operative plan for a patient with a small lung nodule. The size, solid versus ground glass, depth, and location in the lung lobe all are important factors. Subpleural lesions, even ground-glass ones, can always be located and readily removed without preoperative marking. Port placement is important for small nodules, both for easy palpation of the lesion and for placement of the stapler to resect the lesion without undue torqueing on the port site. Most solid nodules $1 \mathrm{~cm}$ or less in depth can be readily found and removed. Ground-glass lesions with higher attenuation also usually can be found within $1 \mathrm{~cm}$ of the visceral pleura. Deep lesions $(\geq 2 \mathrm{~cm})$ are always problematic. The location within the lobe (not mentioned in this study) is important because lesions close to an acute angle of the lung (ie, the tip of the superior

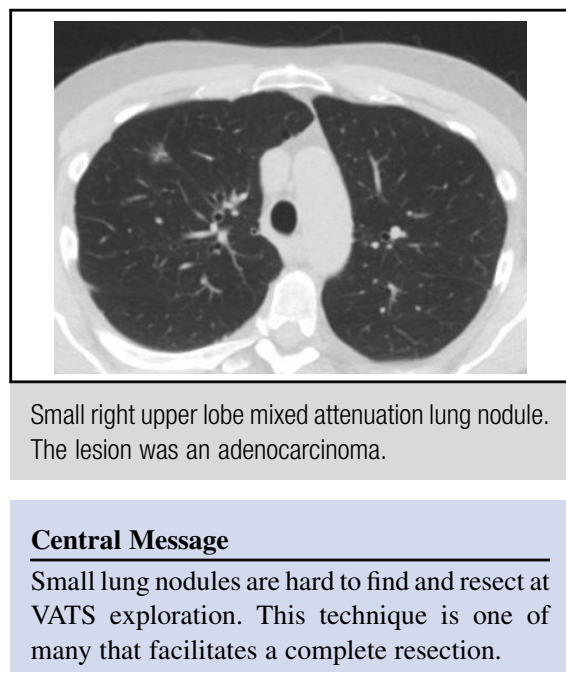

See Article page 1691.

segment of the lower lobe, the apex of the upper lobe, the acute angle of the diaphragmatic edge of the lower lobe) are easier to find and completely resect. Deep nodules along the broad surface of the lobe are harder to resect with adequate margins. Deep nodules often require an extended segmentectomy to obtain adequate margins as the segmental margins narrow centrally limiting margin width.

With these considerations in mind, Dr Sato and colleagues ${ }^{6}$ report a multicenter trial of virtual-assisted lung mapping of 203 nodules in 153 patients. Ground-glass lesions accounted for $36 \%$ of patients. Patients underwent bronchoscopic localization based on a preoperative CT scan (virtual bronchoscopy), which allowed them to target selected peripheral bronchi close to the lesion. A small amount of indigo carmine dye was injected to guide the resection. This could be done on the day of the resection or 1 to 2 days beforehand. Wedge resection was performed in $71 \%$ of patients, and segmentectomy was performed in $28 \%$ of patients. The mean size of the nodule was $9.6 \mathrm{~mm}$, and the mean depth was $10.4 \mathrm{~mm}$. Successful resection was defined as a resection margin greater than the lesion diameter or greater than $2 \mathrm{~cm}$. The predetermined study goal was achievement of a successful resection in $95 \%$ of patients. The lesion was successfully resected in $89 \%$ of patients when the lesion depth was less than $2 \mathrm{~cm}$. Multivariable analysis indicated that the depth of the necessary resection margin was the most important factor predicting a successful resection. Poor dye marking was noted in $14 \%$ of patients, and the most common reasons 
cited were central lesion location, anthracotic lung, and emphysema. Almost all resections were performed with VATS $(98 \%)$ ). Surgeons judged $54 \%$ of lesions not removable without the aid of virtual-assisted lung mapping.

How might thoracic surgeons incorporate this study in their pursuit of complete resection of small lung nodules? Depending on local resources and expertise, this technique seems worthy of further explorations and refinement. Navigational bronchoscopy is not uniformly practiced and in some institutions lies outside the realm of thoracic surgery and is performed by interventional pulmonologists. Thus partnership with an interventional pulmonologist might be necessary in some institutions. Local expertise and institutional results with other localization modalities will likely continue to shape a thoracic surgeon's localization paradigm. I think this is likely to be a short-lived problem as robotic surgery matures. I envision a smart robot incorporating the preoperative $\mathrm{CT}$ in its prescription for a resection plan that has inputs of port placement and anatomic landmarks of the deflated lung to facilitate a complete resection.

\section{References}

1. Grogan EL, Jones DR, Kozower BD, Simons WD, Daniel TM. Identification of small nodules: technique of radio-traced guided thoracoscopic biopsy. Ann Thorac Surg. 2008:85:772-7.

2. Sancheti MS, Lee R, Ahmed SU, Pickens A, Fernandez FG, Small WC, et al Percutaneous fiducial localization for VATS wedge resection of small pulmonary nodules. Ann Thorac Surg. 2014;91:1914-9.

3. Seo JM, Lee HY, Kim HK, Choi YS, Kim J, Shim YM, et al. Factors determining successful CT guided localization of lung nodules. J Thorac Cardiovasc Surg. 2012;143:809-14.

4. Mayo JR, Clifton JC, Powell TI, English JC, Evans KG, Yee J, et al. CT-guided placement of microcoils to direct VATs surgical resection. Radiology. 2009;250: 576-85.

5. Khereba M, Ferraro P, Duranceau A, Martin J, Goudie E, Thiffault V, et al. Thoracoscopic localization of intraparenchymal pulmonary nodules using direct intracavitary thoracoscopic ultrasonography prevents conversion of VATS procedures to thoracotomy in selected patients. J Thorac Cardiovasc Surg. 2012;144:1160-6.

6. Sato M, Kobayashi M, Kojima F, Tanaka F, Yanagiya M, Kosaka S, et al. Effect of virtual-assisted lung mapping in acquisition of surgical margins in sublobar lung resection. J Thorac Cardiovasc Surg. 2018;156:1691-701. 